\title{
KNOWLEDGE ON STROKE AMONG MIDDLE AGED ADULT IN A COMMUNITY AT RATUWAMAI, MORANG
}

\author{
Suvekshya Silwal', Sapana Khadka ${ }^{2}$, Bimala Kumari Sah ${ }^{3}$
}

\begin{abstract}
Stroke is a medical emergency also known as Cerebrovascular Accident (CVA) or "brain attack". Nowadays, this health problem is increasing tremendously day by day in developing country like Nepal.This study follows with an objective to assess the knowledge on stroke among middle aged adult. A descriptive cross-sectional study was used to assess the level of knowledge on stroke among (40-65) years of aged group in a community of Ratuwamai, Morang. Non probability purposive sampling method was used to select respondents where sample size was 117 . Semistructured interview questionnaire was used for data collection and data was analyzed with Statistical Package for Social Science (SPSS) version 16. The study showed that among 117 respondents, 62.1\% were above 50 years $(\mathrm{Mean} \pm \mathrm{SD}=53.53 \pm 7.169), 32.9 \%$ had achieved secondary level of education, $97.4 \%$ gave correct response as stroke is a brain problem, similarly $100 \%$ of respondents reported high risk is above 45years of age, 91.5\% identified hypertension leading to stroke, $96.6 \%$ thought that sudden onset of dizziness as warning signs of stroke. This study found that overall knowledge regarding stroke was average $(65.8 \%)$. Relationship of ethnicity $(p=0.045)$ and level of education( $p=0.000$ )were found to be associated with level of knowledge. A widespread awareness program is required to improve the knowledge of community people regarding stroke, which in turn might improve the control of risk factors, early treatment and better outcomes.
\end{abstract}

Keywords: Stroke, Knowledge, Middle Aged Adult, Community people

1 Ms. Silwal is a Nursing Instructor, Biratnagar Nursing Campus, Morang, TU.

2 Ms. Khadka is RN, School of Medical Science, Dhulikhel Hospital, KU.

3 Ms. Sah is an Assistant Professor, Maharajgunj Nursing Campus, Kathmandu, TU. 


\section{INTRODUCTION}

Stroke is a medical emergency which occurs when the blood supply to the brain is interrupted or reduced either blocked by clot or burst, as result the brain cells begin to die within minutes depriving brain tissue of oxygen and nutrients.

Stroke or Cerebrovascular disease (CVD) is neurological condition with rapidly increasing burden in many low-and middle income countries. According to World Health Organisation (cited in Ayeshah et al. 2018), stroke is defined as rapidly developing signs of focal (or global) disturbance of cerebral function, leading to death or lasting longer than 24 hours, with no apparent cause other than vascular.

Worldwide, stroke is considered the second leading cause of death, accounting for $11.8 \%$ of all deaths in 2013. In the Unites States (US), approximately 795,000 people have stroke every year (Aldayel, Alherbi, Shadid \& Zevallos 2017). Each year 800,000 people experience a new or recurrent stroke. Stroke is the fifth leading cause of adult disability and death in the U.S. (NSA 2018). In the world, 80 million people have had a stroke and some 50 million stroke survivors live with some form of permanent disability (WSO 2019). It is leading cause of disability and mortality worldwide. Of the estimated 795, 000 new or recurring strokes that occur in the United States each year, approximately 145, 000 will result in death. For the 6.5 million individuals who survive after stroke and are alive today, nearly half will have moderate to severe neurological deficits. In addition to the personal toll on health, stroke cost the United States an estimated $\$ 73.7$ billion in 2010 (WSO 2015).

Stroke is one of the leading causes of functional impairments, with $20 \%$ of survivors requiring institutional care after 3 months and $15 \%-30 \%$ being permanently disabled in Asian countries. Patient with multiple risk factors of age group 45-65 years have higher chance of suffering from stroke with their advancing age (Shrestha et al. 2011).

Regarding situation of stroke in the world, Nepal ranks $97^{\text {th }}$ in the world top causes of death with age adjusted standardized death rate of 80.03 per 100,000 population in Nepal, stroke is top $3^{\text {rd }}$ causes of death among top 50 causes of death with 15,450 deaths per 100,000 population in a year (WHO 2017).

Based on disability-adjusted life years, stroke is one of the major causes of death and is among the top five diseases in Nepal. The age of stroke patients in Nepal is between 59 and 62 years, where male affected more 
frequently and ischemic stroke is more common (63\%) than hemorrhagic stroke (37\%) (Shaik et al. 2012).

Globally, Stroke is raising problem where as Nepal is also facing challenges related to stroke which includes lack of specialist and stroke care unit. Some of the studies suggest, knowledge regarding stroke is poor in people of Nepal (Chandra et al. 2019).

\section{MATERIALS AND METHODS}

Descriptive cross-sectional study was used to assess the knowledge on stroke among middle aged in a community at Ratuwamai-6 of Morang district in the Koshi Zone of South-Eastern Nepal which had a population of 11,079 . The study period was from July 2018 to January 2019. The study population included age group of 40-65 years. Non probability purposive sampling method was used to select respondents. Semi-structured interview questionnaire was used to obtain information by interviewing face to face for each respondents. It consists of two parts: Part 1- SocioDemographic Information of Middle aged Adult, Part 2-Questionnaire regarding Knowledge on Stroke. Data was entered and analyzed by using Statistical Package for Social Science (SPSS) version 16. Descriptive analysis frequencies, percentage and mean were used to assess the level of knowledge and the inferential analysis Chi-square was used to find out association of knowledge with selected demographic variables. Knowledge score was calculated on the basis of 20 multiple response questions where each correct answer carried 1 mark. Altogether, total score consisted of 40 marks which were then converted into percentage. Poor knowledge: less than 50\%, Average knowledge: $50-75 \%$ and Good knowledge: more than $75 \%$ marks.

\section{RESULTS AND DISCUSSION}

\section{Demographic profile}

Table 1 shows that majority of respondent belonged to Brahmin/ Chhetri which supports of Census (2011) i.e. 28.8\% Brahmin/Chhetri and Janajati $26.8 \%$. In the present study $25.6 \%$ of the respondent had achieved secondary education which is supported by the study conducted on Knowledge and Perception of Stroke: a Population Based Survey in Uganda which indicated $39.5 \%$ had achieved secondary level of education (Nakibuuka et al. 2014). 
34 KNOWLEDGE ON STROKE AMONG MIDDLE AGED ADULT ...

Table 1: Demographic information of middle aged adult $(\mathrm{n}=117)$

\begin{tabular}{|c|c|c|}
\hline Variables & Frequency(f) & Percentage $(\%)$ \\
\hline \multicolumn{3}{|l|}{ Age (in years) } \\
\hline$\leq 45$ & 17 & 14.5 \\
\hline $46-50$ & 26 & 22.2 \\
\hline $51-55$ & 25 & 21.4 \\
\hline $56-60$ & 22 & 18.8 \\
\hline$>60$ & 27 & 23.1 \\
\hline \multicolumn{3}{|c|}{ Mean \pm SD $=53.53 \pm 7.196$} \\
\hline \multicolumn{3}{|c|}{ Sex } \\
\hline Male & 55 & 47 \\
\hline Female & 62 & 53 \\
\hline \multicolumn{3}{|l|}{ Ethnicity\# } \\
\hline Brahmin/Chhetri & 92 & 78.6 \\
\hline Janajati & 25 & 21.4 \\
\hline \multicolumn{3}{|l|}{ Occupation } \\
\hline Farming & 101 & 86.3 \\
\hline Service & 7 & 6.0 \\
\hline Business & 7 & 6.0 \\
\hline Daily wages & 2 & 1.7 \\
\hline \multicolumn{3}{|l|}{ Education } \\
\hline Illiterate & 26 & 22.2 \\
\hline Literate & 91 & 77.8 \\
\hline \multicolumn{3}{|c|}{ Level of education* $(n=91)$} \\
\hline Informal & 27 & 29.7 \\
\hline Primary & 23 & 25.3 \\
\hline Secondary & 30 & 32.9 \\
\hline Higher secondary & 11 & 12.1 \\
\hline \multicolumn{3}{|c|}{ Monthly income (NRs.) } \\
\hline$<10,000$ & 31 & 26.5 \\
\hline $11,000-20,000$ & 82 & 70.1 \\
\hline $21,000-30,000$ & 2 & 1.7 \\
\hline$>30,000$ & 2 & 1.7 \\
\hline
\end{tabular}

Similarly in Table 1, the study indicates $86.6 \%$ of respondents were involved in farming which is supported by the Agriculture Census Nepal (2011) as there shown more than $81 \%$ involved in agriculture. Regarding income in the conducted study, most of the respondents had monthly income of NRs 11,000-20,000 which is contradictory with the study conducted on Awareness of University Students towards Strokes: A Cross-Sectional Study in Bangladesh which showed 44,057 taka (NRs.34,152.71) per 
month (Alam et al. 2017). It might be due to the low qualification and types of occupation followed by respondents that most of them were involved in farming as their main source of income.

Table 2: Knowledge on stroke among middle aged adult $(\mathrm{n}=117)$

\begin{tabular}{|c|c|c|}
\hline Variables & Frequency(f) & Percentage (\%) \\
\hline \multicolumn{3}{|l|}{ Meaning of stroke } \\
\hline Brain problem & 114 & 97.4 \\
\hline Heart problem & 3 & 2.6 \\
\hline \multicolumn{3}{|l|}{ Source of information* } \\
\hline Friends & 98 & 83.8 \\
\hline Television & 79 & 67.5 \\
\hline Family member & 77 & 65.8 \\
\hline Health personnel & 67 & 57.3 \\
\hline Newspaper & 23 & 19.7 \\
\hline Radio & 21 & 17.9 \\
\hline Internet & 14 & 12 \\
\hline \multicolumn{3}{|l|}{$\begin{array}{l}\text { Existing health problems } \\
\text { (diagnosed) }\end{array}$} \\
\hline Hypertension & 7 & 6.0 \\
\hline Diabetes mellitus & 1 & 0.9 \\
\hline \multicolumn{3}{|l|}{ Transmission } \\
\hline Yes & 2 & 1.7 \\
\hline No & 115 & 98.3 \\
\hline \multicolumn{3}{|l|}{ Mostly affected } \\
\hline Both male and female & 110 & 94 \\
\hline Male & 5 & 4.3 \\
\hline Female & 2 & 1.7 \\
\hline \multicolumn{3}{|l|}{ High risk age } \\
\hline$<45$ years & 0 & 0 \\
\hline$>45$ years & 117 & 100 \\
\hline
\end{tabular}

* Multiple response questions, each response is considered 100\%

Table 2 depicts 3.4\% reported hypertension as existing health problem which is contradictory with the study conducted on a Crosssectional population survey on stroke knowledge and attitudes in Greater Kampala, Uganda. Out of 440 adults screened $17.5 \%$ had hypertension it might possibly of difference in sample size in present study among 117 respondents and in previous study among 440 respondents (Kaddumukasa et al. 2017). 


\section{Level of knowledge on stroke among middle aged}

Table 3,4, 5 and 6 indicate level of knowledge on stroke among middle aged, most of the $(65.8 \%)$ respondent had average knowledge which is similar to the study conducted on knowledge of risk factors and warning signs of stroke which revealed $67.24 \%$ of respondent of age group 40-60 years had average knowledge on stroke (Nicol \& Thrift 2005). One study (Wiszniewska, et al. 2000) conducted in Poland that knowledge of stroke among adults revealed that a correct definition of stroke was given by $86.7 \%$ of the respondents. Only a small proportion of them knew risk factors for stroke $(27.8 \%$ knew that one of them was hypertension, $6.1 \%$ gave smoking, $4.4 \%$ diabetes as risk factors).Similarly one study conducted in China concluded that the urban community residents in China are lacking in knowledge about stroke (Haixin et al. 2011).

One study conducted in rural area of Nepal about knowledge of stroke among higher secondary school students (1360 participants) revealed that $71.1 \%$ had heard or read about stroke; $30.2 \%$ knew someone with stroke, $39.3 \%$ identified brain as the organ affected. Sudden onset limb/s weakness/numbness (72\%) and hypertension (74\%) were common warning symptom and risk factor identified, $88.9 \%$ would take stroke patients to a hospital. Almost half participants (55.5\%) felt ayurvedic treatment be effective, $44.8 \%$ felt stroke as a hindrance to a happy life and $86.3 \%$ believed that family care was helpful for early recovery (Thapa et al. 2016). Tosome extent this study findings are contrast from present study findings.

\section{Association of socio-demographic variables with level of knowledge}

The present study do not shows the relationship of age and sex with the level of knowledge on stroke with p-value is 0.875 for age and 0.529 for sex similar result were obtained from the study conducted on Knowledge of Risk factors and Warning signs of stroke among Middle age, with p-value 0.126 for age and 0.317 for sex (Nicol \& Thrift 2005).

However the level of education is significant predictor of good knowledge, the study shows the association of education level with knowledge on stroke with p-value 0.000 alike the study conducted on Stroke Awareness in general Population: Knowledge of Stroke Risk factors and Warning signs which showed p-value 0.001 (Hickey et al. 2009). Similarly another study suggests low education is associated with increased stroke risk in men and women, and may be marginally steeper in women than men. Modifiable risk factors account for much of the excess risk from low education level (Jackson et al. 2018). The present study reflects association of ethnicity with the level of knowledge with p-value 0.045 
which is supported by the study where Hispanics and Blacks had higher odds of stroke in comparison with non-Hispanic Whites and proposes an association between race/ethnicity and the prevalence of stroke (Aldayel et al. 2017).

Table 3: Knowledge on risk factor, symptoms and prevention of stroke $(\mathrm{n}=117)$

\begin{tabular}{|c|c|c|}
\hline Variables & Frequency(f) & Percentage $(\%)$ \\
\hline \multicolumn{3}{|l|}{ Factors lead to stroke* } \\
\hline Hypertension & 107 & 91.5 \\
\hline Stress & 100 & 85.4 \\
\hline Smoking & 32 & 27.4 \\
\hline Obesity & 18 & 15.4 \\
\hline Sedentary life style & 5 & 8.5 \\
\hline Diabetes & 3 & 4.3 \\
\hline \multicolumn{3}{|l|}{ Warning signs of stroke* } \\
\hline Sudden onset of dizziness & 114 & 97.4 \\
\hline Sudden onset of headache & 111 & 94.9 \\
\hline $\begin{array}{l}\text { Sudden onset of weakness/ } \\
\text { numbness arms and legs }\end{array}$ & 31 & 26.5 \\
\hline Sudden onset of fainting & 22 & 18.8 \\
\hline Sudden onset of double vision & 10 & 8.5 \\
\hline \multicolumn{3}{|l|}{ Symptoms of stroke* } \\
\hline Dizziness & 113 & 96.6 \\
\hline Slurred speech & 62 & 53 \\
\hline Facial drooping & 55 & 47 \\
\hline Weakness of arms and leg & 55 & 47 \\
\hline $\begin{array}{l}\text { Problem with balance and co- } \\
\text { ordination }\end{array}$ & 55 & 47 \\
\hline Blacking out & 42 & 35.9 \\
\hline \multicolumn{3}{|l|}{ Prevention of stroke* } \\
\hline Consuming healthy diet & 99 & 84.6 \\
\hline Control blood pressure & 78 & 66.7 \\
\hline Avoid smoking & 70 & 59.8 \\
\hline Avoid alcohol & 67 & 57.3 \\
\hline Exercise & 49 & 41.9 \\
\hline Control blood sugar & 3 & 2.6 \\
\hline
\end{tabular}

* Multiple response questions, each response is considered 100\%

This study doesn't show the association of occupation with knowledge on stroke with p-value 0.066 is supported by the study conducted on Awareness of University Students towards Strokes: A Cross-Sectional Study which shows $p$-value 0.085 (Alam et al. 2017. In the present study existing health problems and income do not reflect the association with 
knowledge on stroke with $p$-value 0.574 for income and 0.67 for existing health problems which is contradictory to the previous study on Knowledge of Stroke Risk Factors, Warning Symptoms, and Treatment among an Australian Urban Population with $\mathrm{p}$ value 0.005 for health problems and 0.01 for income it might be due to setting difference, rural area in present study where as urban area in previous study (Yoon et al. 2001).

Table 4: Knowledge on treatment of stroke among middle aged adult $(\mathrm{n}=117)$

\begin{tabular}{lrr}
\hline Variables & Frequency(f) & Percentage(\%) \\
\hline Can stroke be cured & 71 & 60.6 \\
$\quad$ Yes & 46 & 39.4 \\
$\quad$ No & & \\
Treatment of stroke (primary & & \\
preference) & 113 & 96.6 \\
$\quad$ Allopathic & 4 & 3.4 \\
$\quad$ Ayurvedic & & \\
Stroke patient recover to normal & 4 & 3.4 \\
$\quad$ Yes & 113 & 96.6 \\
$\quad$ No & & \\
Responsible for recovery of stroke & & \\
patient* & 112 & 95.7 \\
$\quad$ Health care personnel & 46 & 39.3 \\
$\quad$ Family member & 34 & 29.1 \\
$\quad$ Physiotherapy team & 13 & 11.1 \\
$\quad$ Patient themselves & & \\
Importance of rehabilitation & 74 & 63.2 \\
$\quad$ Yes & 43 & 36.8 \\
$\quad$ No & & \\
Ways of rehabilitation ( & $\mathbf{n}=\mathbf{7 4 )}$ & 90.4 \\
$\quad$ Depends on the kind of problem & 7 & 9.6 \\
$\quad$ Physiotherapy only & & \\
Immediate management for fainting & & \\
and loss of consciousness & & \\
$\quad$ Take person to hospital & & \\
$\quad$ Wait for spontaneous recovery & 114 & 1.7 \\
$\quad$ Leave him/her alone & 2 & 0.9 \\
\hline
\end{tabular}

* Multiple response questions, each response is considered 100\% 
Table 5: Level of knowledge on stroke among middle aged adult $(n=117)$

\begin{tabular}{lrr}
\hline Variables & Frequency(f) & Percentage(\%) \\
\hline Poor & 32 & 27.4 \\
Average & 77 & 65.8 \\
Good & 8 & 6.8 \\
\hline
\end{tabular}

Table 6: Association of level of knowledge with selected demographic variables $(\mathrm{n}=117)$

\begin{tabular}{|c|c|c|c|}
\hline \multirow[t]{2}{*}{ Variables } & \multicolumn{3}{|c|}{ Level of knowledge } \\
\hline & Inadequate f \%) & Adequate f $(\%)$ & p value* \\
\hline \multicolumn{4}{|l|}{ Agegroup (in years) } \\
\hline $40-50$ & $7(5.9)$ & $36(30.7)$ & .053 \\
\hline $51-65$ & $25(21.4)$ & 49(41.9) & \\
\hline \multicolumn{4}{|l|}{ Sex } \\
\hline Male & 11(9.4) & $44(37.6)$ & 0.102 \\
\hline female & 21(17.9) & $41(35.1)$ & \\
\hline \multicolumn{4}{|l|}{ Ethnicity } \\
\hline Brahmin/Chhetri & $32(27.3)$ & $71(60.7)$ & $.045^{*}$ \\
\hline Janajati & $0(.0)$ & $14(12.0)$ & \\
\hline \multicolumn{4}{|l|}{ Education } \\
\hline Illiterate & $19(16.2)$ & $7(5.9)$ & $.000 *$ \\
\hline Literate & $13(11.1)$ & $78(66.6$ & \\
\hline \multicolumn{4}{|l|}{ Educational level $(n=91)$} \\
\hline \multicolumn{4}{|l|}{ Informal } \\
\hline Primary level & $7(7.6)$ & $20(21.9)$ & $.000 *$ \\
\hline Secondary level & $2(2.1)$ & $21(23)$ & \\
\hline \multirow[t]{2}{*}{ Higher secondary level } & $3(2.6)$ & $27(29.6)$ & \\
\hline & - & $11(12.0)$ & \\
\hline \multicolumn{4}{|l|}{ Occupation } \\
\hline Farming & $31(26.5)$ & $0(59.8)$ & \\
\hline Others\# & 1(.9) & $15(12.8)$ & 0.066 \\
\hline \multicolumn{4}{|l|}{ Monthly Income (in NRs) } \\
\hline$\leq 20,000$ & $32(27.4)$ & $81(69.2)$ & 0.574 \\
\hline$>20,000$ & $0(0)$ & $4(3.4)$ & \\
\hline \multicolumn{4}{|l|}{ Existing health problems } \\
\hline Hypertension & $3(2.6)$ & $4(3.4)$ & 0.657 \\
\hline Diabetes & $0(0)$ & $1(0.9)$ & \\
\hline
\end{tabular}

*Chi-square test p-value significance i.e. $<0.05$

\# includes service, business and daily wages 


\section{CONCLUSION}

The study concluded that there was average knowledge on stroke among middle aged adult hence, there is a need for further study in view of understanding the knowledge on Stroke. Widespread awareness program focusing on prevention of risk factors on stroke can be conducted among community people to reduce the stroke occurrence.

\section{REFERENCES}

Alam, M.M., Nishat,S.A., Rahman,S., Halim,A., Rahaman, M.M. \&Islam, M. (2017). Awareness of university students towards strokes: A cross-sectional study. Journal of Biomedical and Pharmaceutical Research, 6(3): 45. https://www.researchgate.net/ publication/321714226. (Accessed: 18.06.2018).

Aldayel, A.Y., Alharbi, M. M., Shadid, A. M. \& Zevallos, J.C. (2017). The association between race/ethnicity and the prevalence of stroke among United States adults in 2015: a secondary analysis study using behavioural risk factor surveillance system (BRFSS). Electron Physician. 9(12): 5871-5876. doi: 10.19082/5871. (Accessed: 18.06.2018).

Ayeshah, A., Faisal, A., Abdulrahman, A., Dalia, A., Alaa, A., Fatimah, A., Reem, A.(2018). Types and risk factors of cerebrovascular disease among adult patients admitted in kkuh in Riyadh City: A case control study. Ecronicon Neurology. 10(2): 24-33.

Chandra, A., Rajbhandari, P. \& Pant, B. (2019). Acute stroke management. Americian Academy of Neurology. doi: 10.1212/ WNL.0000000000007528. (Accessed: 23.07.219).

Haixin, S., Shengyun, C., Bin, J., Xingquan, Z., Shengping, W., Yunhai, L., Jiuyi, H., Li, H. \& Wenzhi, W. (2011). Public knowledge of stroke in Chinese urban residents: a community questionnaire study, Neurological Research, 33(5): 536540. doi: 10.1179/016164111X13007856084368 (Accessed: 01.07.2018).

Hickey, A., Hanlon, A.O., Gee, H.M., Donnellan, E.S., Horgan, F. \& Neill, C. (2009). Stroke awareness in the general population: knowledge of stroke risk factors and warning signs in older adults. Bio Med Central Geriatric, 1-8. doi: 10.1186/1471-2318-9-35 (Accessed: 20.06.2018). 
Jackson, C.A., Sudlow, C. L. M., \& Mishra, G.D. ( 2018). Education, sex and risk of stroke: a prospective cohort study in New South Wales, Australia. BMJ Open. 8(9): 24-70. doi: 10.1136/ bmjopen-2018-024070 (Accessed: 04.07.2018).

Kaddumukasa, M., Kayima, J., Nakibuuka, J., Mugenyi, L., Ddumba, E., Blixen, C., \& Sajatovic,A. (2017). A cross-sectional population survey on stroke knowledge and attitudes in Greater Kampala, Uganda. Cogent Medicine 12. https://doi.org/10.1080/233120 5X.2017.1327129 (Accessed: 18.07. 2018).

Nakibuuka, J., Sajatovic, M., Katabira, E., Ddumba, E., Tusiime, J.B. \& Furlan, A.J. (2014). Knowledge and perception of stroke: A population-based survey in Uganda. Hindawi Publishing Corporation. doi: 10.1155/2014/309106 (Accessed: 21.072018).

NSA. (2016). Stroke by the numbers. National Stroke Association (NSA). http://www.stroke.org/understand-stroke/what-stroke (Accessed: 22.07.2018).

Nicol, M.B. \& Thrift, A.G. (2005). Knowledge of risk factors and warning signs of stroke. Vascular Health and Risk Management 1(2): 137147. https://www.ncbi.nlm.nih.gov/pmc/articles/PMC1993942/ (Accessed: 16.04.2018).

Shaik, M.M., Loo, K.W. \& Gan, S.H. (2012). Burden of stroke in Nepal. SAGE Journal of Stroke, 1(2). doi:10.1111/j.17474949.2012.00799.x.2012.06.013 (Accessed: 30.06.2018).

Shrestha, A., Shah, D.B., Koirala,S.R., Adhikari, K.R., Sapkota, S. \& Regmi, P.R. (2011). Retrospective analysis of stroke and its risk factors at Bir Hospital. Postgraduate Medical Journal of NAM 11(2): 28-30. https://pmjn.org.np/index.php/pmjn/article/viewFile/58/56 (Accessed: 18.04.2018).

Thapa, L., Sharma, N., Poudel, R.S., Bhandari, T.R., Bhagat, R., Shrestha, A. \& Caplan, L.R. (2016). Knowledge, attitude, and practice of stroke among high school students in Nepal. Journal of Neurosciences in Rural Practice, 7(4): 504. https://www.ncbi.nlm.nih.gov/pmc/ articles/PMC5006460/ (Accessed: 02.07.2018).

Wiszniewska, M., Swiderski, W., Fryze, W., Drozdowski, W., Hertmanowska, H., Włodek, A. \& Członkowska, A. (2000). Knowledge of stroke problems among adults in Poland.Neurologiaineurochirurgiapolska 
34(6): 1129-1136. https://europepmc.org/abstract/med/11317489 (Accessed: 03.08.2019).

WHO. (2017). WHO World health ranking: Live longer live better. World Health Organization. https://www.worldlifeexpectancy.com/ country-health-profile/nepal/ (Accessed: 06.07.2018).

WSO. (2015). WHO facts and figures. World Stroke Organisation (WSO). https://www.worldstrokecampaign.org/learn/facts-and-figures. html\%20on\%202018/4/24 (Accessed: 24.04.2018).

WSO. (2019). World stroke day events 2018. World Stroke Organization (WSO). https://www.worldstrokecampaign.org/ (Accessed: 18.09.2019).

Yoon, S.S., Heller, R.F., Levi, C., Wiggers, J. \& Fitzgerald, P.E. (2001). Knowledge of stroke risk factors, warning symptoms, and treatment among an Australian urban population. American Heart Association Journal. 32(8): 1926-1930. doi: 10.1161/01. STR.32.8.1926 (Accessed: 16.08.2018). 